\title{
Development of an Improved Electronic Learning Management System
}

\author{
Frimpong D. \\ University for Development \\ Studies \\ Department of Computer \\ Science \\ Navrongo, Ghana
}

\author{
Alhassan A. \\ University for Development \\ Studies \\ Department of Computer \\ Science \\ Navrongo, Ghana
}

\author{
Akobre S. \\ University for Development \\ Studies \\ Department of Computer \\ Science \\ Navrongo, Ghana
}

\begin{abstract}
The main aim of this research is to develop an improved electronic learning management system (ImEMMS) that will enhance the flexibility of learning between learners and tutors. The work is an improvement of the EWEBAMOLEMAS system developed in 2015. New features such, as Video Tutorial platform and Quiz platform have been added to enhance the ImEMMS system. Rapid Application Development methodology was deployed in the system development and implemented on a Wamp server.
\end{abstract}

\section{General Terms}

Improved Electronic Learning Management System (ImEMMS), Software Development, Rapid Application Development.

\section{Keywords}

ImEMMS, Wamp Server, Improved Electronic Learning Management System.

\section{INTRODUCTION}

The spontaneous growth of mobile and handheld devices in our world today have geared mobile learning in becoming an efficient tool for teaching and learning. Mobile learning reduces the complicated and repeated work of tutors and allow them to have materials that is readily available to learners even when a tutor is far away from campus [7]. In mobile learning environment, devices such as PDAs, tablets, PCs, smartphones and notebook computers have been used to enhance learning. Students can access video tutorials, lecture notes and audio-based lessons anytime and at anywhere they are [3]. In the mobile learning environment, students who are shy can have access to ask relevant questions via video conferencing and contribute as well in class. Students who are far away from campus can also participate in class activities by adding comments and submitting assignment electronically. Educators can also perform quizzes and evaluate learners without assembling all students in one class. Several sophisticated electronic devices have been developed over the years, yet few mobile learning softwares have been developed for the University for Development Studies to help both learners and tutors to have a smooth learning environment. This application software (ImEMMS) is developed mainly to assist learners and tutors of the University for Development Studies who are far away from campus and cannot attend class to take part in class activities. Tutors can send video tutorials, lecture notes and quizzes via the internet onto the system for students to access whiles they are off campus. A student, with internet connection can have access to lecture materials uploaded by a lecture. The ImEMMS software is very responsive and can be access on any device irrespective of the screen size [5].

\section{PROBLEM STATEMENT}

Over the years, learning in the University for Development Studies have been conventional. This discourages disable students from attending classes whenever they are late. With the invention of the ImEMMS software, students can have access to lecture materials and take part in quizzes whenever they are far away from campus.

\section{METHODOLOGY AND TOOLS}

In this section, we talk about the methodology and tools that were deployed in the development of the Improved electronic learning management system. Rapid Application Development methodology was used due to the quick and the simple nature of the methodology. Considering the time range given for the software, this methodology was of high essence. Tools such as PHP designer and WAMP server was used for the implementation of the ImEMMS system.

\subsection{Rapid application Development}

The RAD methodology is one of the quickest methodology for developing a software [2]. Unlike other methodologies, the $\mathrm{RAD}$ involves four major phases. These are

$$
\begin{aligned}
& >\text { Requirements phase } \\
& >\text { System Design phase } \\
& >\text { System Development phase } \\
& >\text { Implementation phase }
\end{aligned}
$$

\subsubsection{Requirement phase}

This is the initial phase of the RAD where information about the development of the system is gathered from the users of the system. In this case, data were taken from the school's administration, tutors and learners. This was done in order to get the necessary information from the uses to be able to include them to the system.

\subsubsection{System Design phase}

The system design phase is the next phase after the initial phase. Here, the blueprint of the system is designed for users to make their final deduction before developing the software. This enables both users and developers to get a clear understanding of the software being developed.

\subsubsection{System Development phase}

Here, the actual system is developed by the developers. The ImEMMS system was developed with few templates from Bootstraps and PHP designer. In this phase the coding of the actual system is done. Prototype of the system is shown to the users for confirmation and any changes required is done for a final installation of the system. 


\subsubsection{Implementation phase}

This is the final phase of the RAD methodology where the final system is tested and installed for the users. The system is maintained and updated to meets the current requirements of the users.

\subsection{Tools}

PHP designer is the IDE used to design the ImEMMS system. HTML, CSS, JavaScript and templates from Bootstrap are the language used to develop the system. The ImEMMS system was implemented on a Wamp server and Firefox for further testing. A server side scripting language used is the PHP [4]

Table 1. Hardware requirements of ImEMMS

\begin{tabular}{|l|l|}
\hline Hardware & Minimum requirements \\
\hline Processor & $1 \mathrm{GH}$ speed and above \\
\hline Memory & $500 \mathrm{MB}$ (recommended) \\
\hline Disk space & $10 \mathrm{~GB}$ (for database) \\
\hline Display & $800 \times 600$ colors \\
\hline
\end{tabular}

Table 2. Software requirements of ImEMMS

\begin{tabular}{|l|l|}
\hline Software & Minimum requirement \\
\hline Operating system & Windows, Android, Mac \\
\hline Database & MYSQL \\
\hline Runtime & Apache \\
\hline
\end{tabular}

\section{RESULTS AND DISCUSSIONS}

The improved electronic learning management system (ImEMMS) is designed mainly to improve the learning environment between learners and tutors of the University for Development Studies. The system is an improvement of a similar work conducted by [6]. The system is hosted locally on a Wamp server. The interfaces of the system were developed using HTML and CSS. MySQL is used for the database. The homepage consists of the Students, Lecturer and the Administrator portal. Here, users can login and access documents from their page. The Administrator registers all users onto the system. Once students and lecturers are registered, they can $\log$ on to the system with the required details assigned by the administrator. One advantage of the ImEMMS system is ability to access lecture notes, video tutorials and quizzes. Disabled students who do not make it to class early can access lecture materials uploaded by the lecturer during a course. Lecturers can also evaluate students by uploading quizzes [3]. Once a student takes a quiz, the results is displayed to the students and the marks is sent to the lecturer's portal for recording. In this case, the lecturer will not have to mark voluminous scripts of students. The system is designed to suit the size of smaller devices such as mobile phone. This was a major factor because not all students of the school have devices with larger screen size. A security feature which is of essence is the inability for students to take the quiz twice. Once a student accesses the quiz, the section is disabled until the lecture updates the page with new questions. The results and all details of the student is submitted to the lecturer therefore discouraging students from cheating on the platform. The figures below show snapshots of the results.

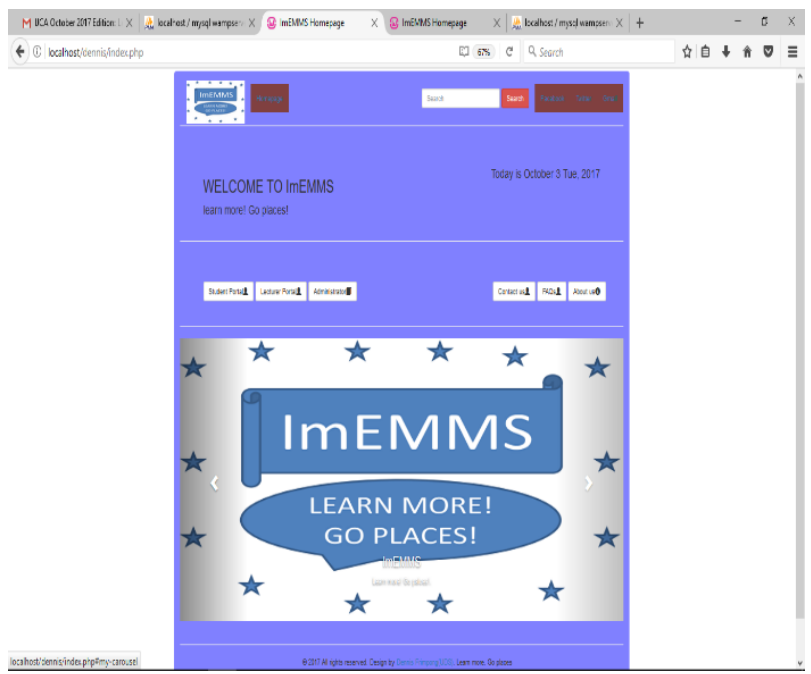

Fig 1: The homepage of the ImEMMS system when accessed on the server

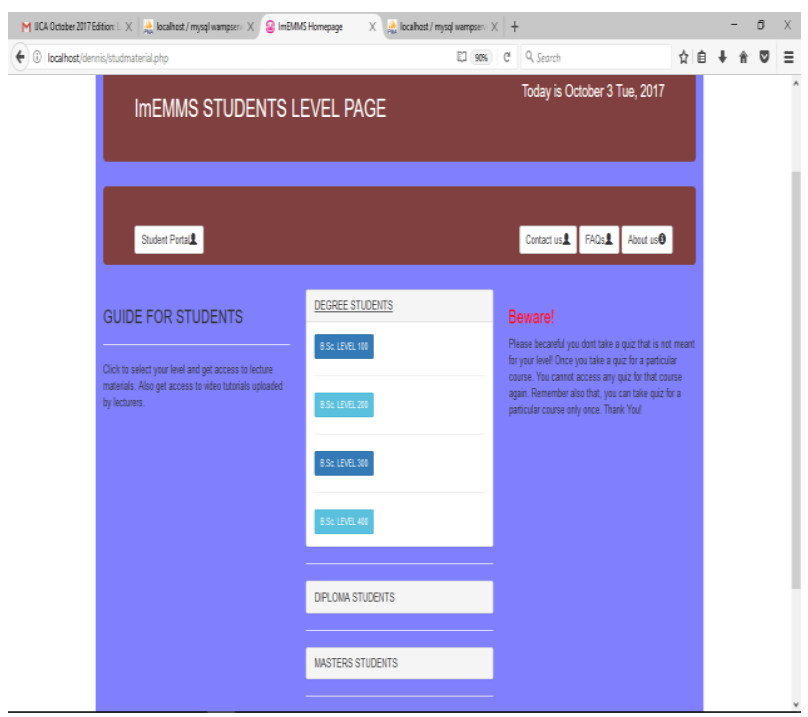

Fig 2: A snapshot of the student page where lecture materials can be accessed 


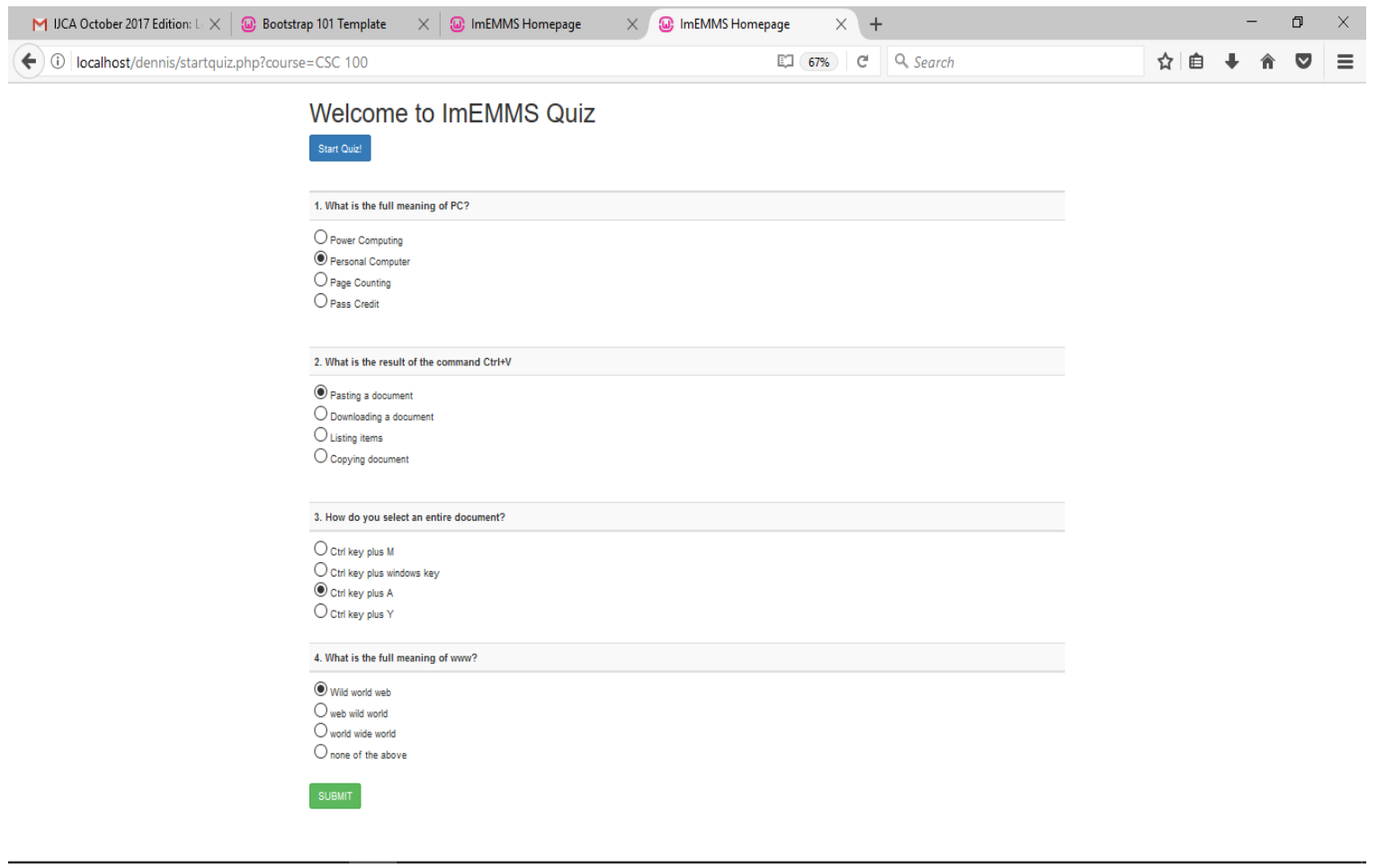

Fig 3: A sample quiz uploaded to the student page

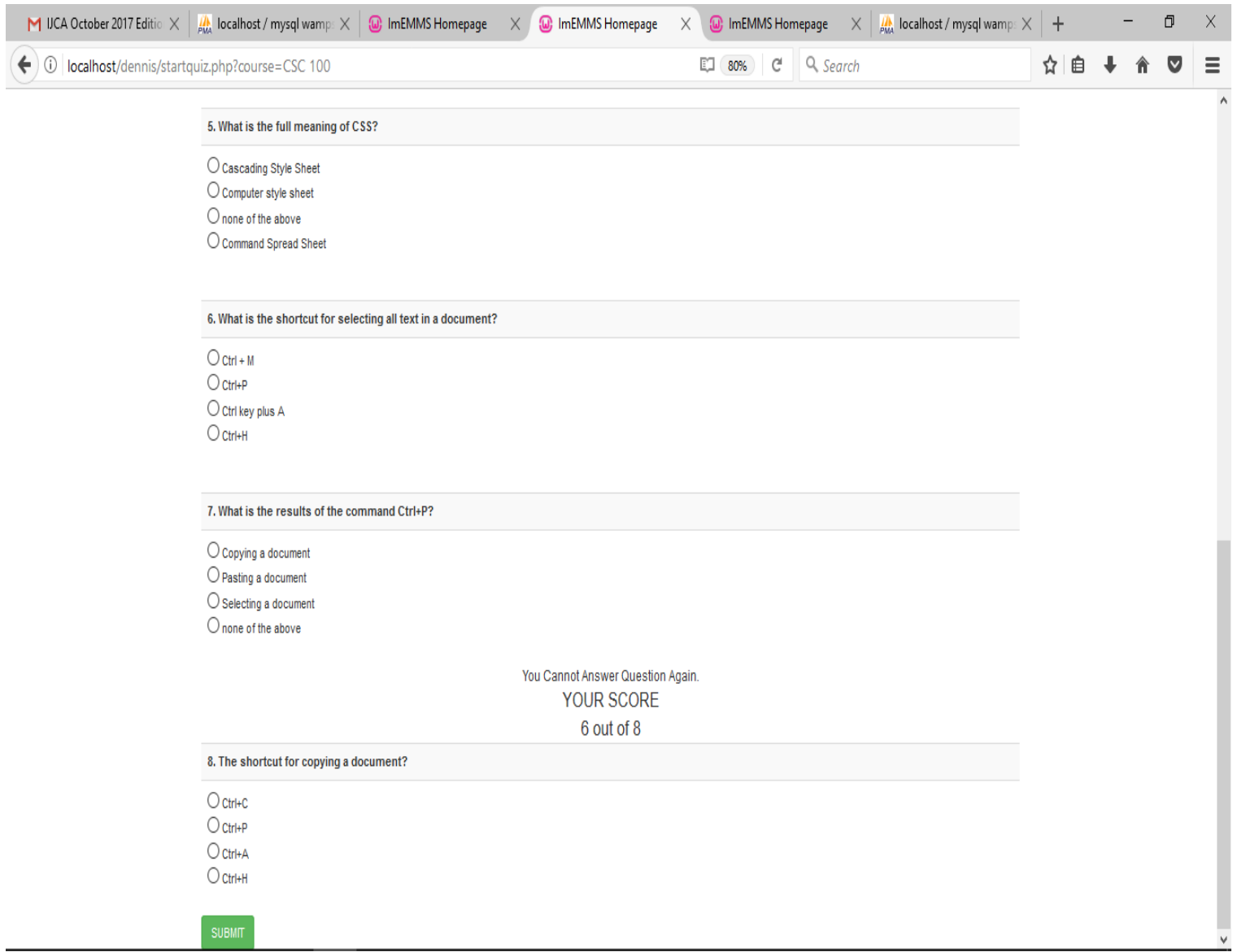

Fig 4: The result is displayed to the student and all details sent to the tutor of the course 


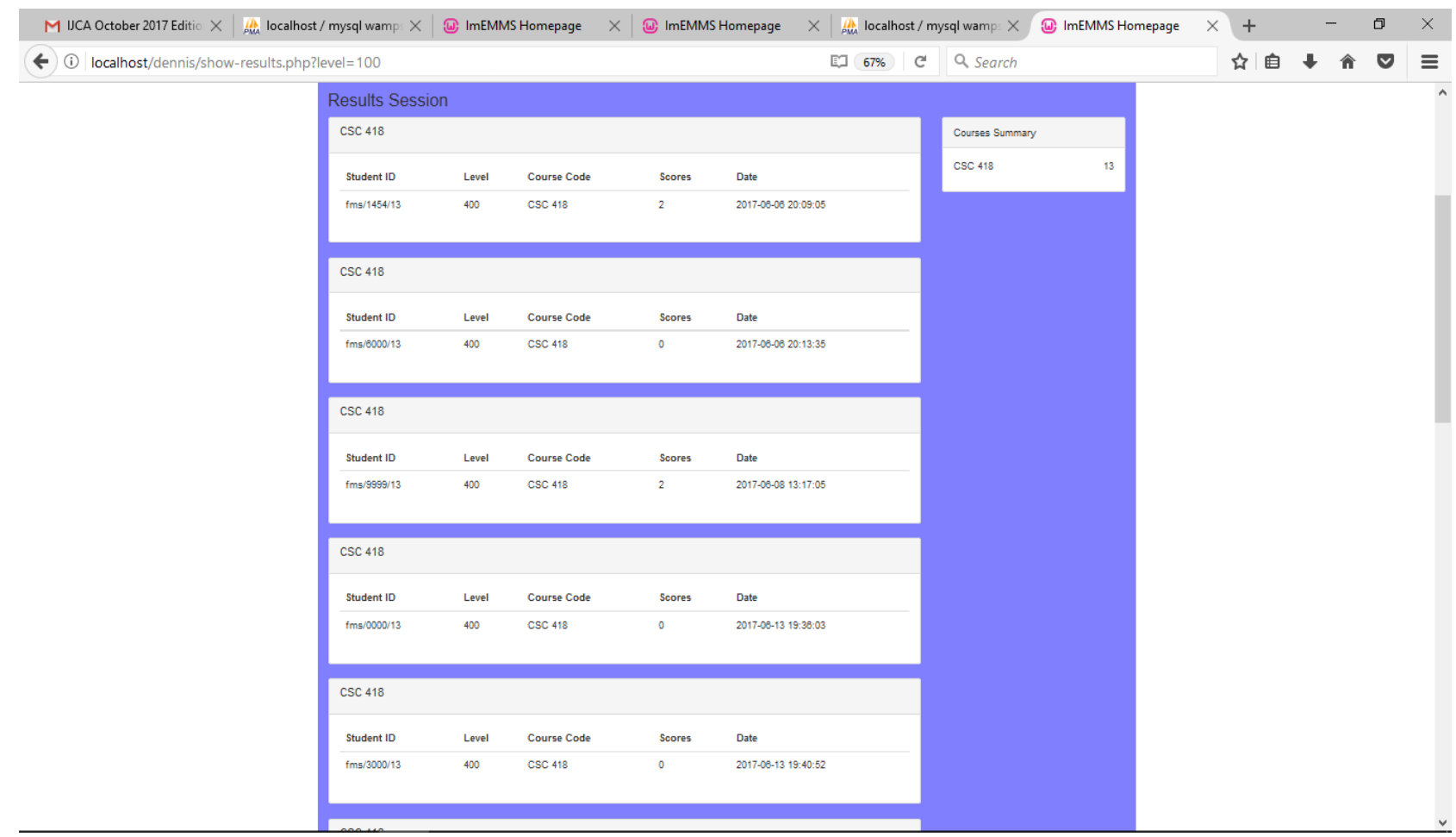

Fig 5: A snapshot of the results summary of all students who have taken the quiz on the tutor's homepage

\section{CONCLUSION}

This proposed system provides a smooth learning environment for both learners and tutors. It supports students who are far away from campus to take part in class activities [1]. Lecturers can evaluate students with quizzes and get details of their results instantly. With this system, the cost of buying and printing out huge volumes of handouts from lecturers can be minimized. The only disadvantage of this system is the fact that, most students may miss classes with the notion that the videos and all materials will be updated onto the system after the class. Notwithstanding, the constant taking of attendance by lecturers can discourage learners for missing class for no reason.

\section{REFERENCES}

[1] Albastroiu, I., and Felea, J. 2016. Mobile learning in higher education.

[2] Antwi, A. E., and Appiah, A. J., 2016 ICT enabled for higher learning institutions in developing nations. Project
Report. University for Development Studies at Navrongo.

[3] D.W. Sahilu, W.F.W. Ahmad, and N.S. Haron "University students' awareness on m-learning", World Academy of Science Engineering and Technology

[4] Welling, P., and Thompson, L. 2009 PHP and MySQL web development. Pearson Education Inc.

[5] Schweitzer, D., and Teel, S. 2011. SHERPA: A mobile application for students and educators in the classroom.

[6] A. Alhassan, A. Rashad, and K.A. Gbolagade "An enhanced web-based platform for mobile learning management system", International Journal of Computer Applications, 2015, 124(16), 30-34.

[7] Romero, C., Ventura, S., and De Bra, P. 2008 Using mobile web-based computerized tests to evaluate university students. 